\title{
The effects of weathering on mechanical properties of kenaf unsaturated polyester composites (KFUPC).
}

\begin{abstract}
Kenaf Fibre reinforced composites have been gaining wide use in the variety of applications. The performance of these composit es may suffer when the material is exposed to adverse environments for long periods of time. Kenaf fibre unsaturated polyester composites (KFUPC) were subjected to three environmental tests: water immersion, soil buried and natural weather tests, in order to study the effect of water/relative humidity absorption on the mechanical properties of specimens containing 10, 20 and $30 \%$ by weight of fibre content. Tensile strength and modulus of the composites were determined. A decrease in tensile properties of the composites was demonstrated, showing a great loss in mechanical properties of the humid samples compared to the dry samples. The percentage of moisture uptake increased as the weight percentage of fibre is increased due to the high cellulose content. The water absorption pattern of these composites was found to follow Fickian behavior.
\end{abstract}

Keyword: Cellulose content; Composite specimens; Fibre content; Moisture uptake; Natural conditions; Natural fibre composites; Natural weathering; Relative humidities; Unsaturated polyester; UV radiation; Weight percentages. 